\title{
Challenges and Issues in Adult Intensive Care Nursing
}

\section{Lise St-Pierre ${ }^{1 *}$, Alderson $\mathbf{M}^{2}$ and Saint-Jean $\mathbf{M}^{3}$}

${ }^{1}$ Directrice de la qualité et des soins infirmiers, Centre de santé et services sociaux de Memphrémagog, principal investigator, Canada

${ }^{2}$ Faculté des Sciences Infirmières, Université de Montréal, Co-Investigator, Canada

${ }^{3}$ Faculté de médecine, Université de Montréal, Co-Investigator, Canada

\begin{abstract}
Until quite recently, many intensive care units (ICU) in Quebec's hospitals provided a very attractive practice option for nurses. Now, however, the retention rate for both experienced and inexperienced nurses in these units is very low. Major recruitment efforts based on various approaches have been attempted but have failed to fill the vacancies. Starting from the standpoint of the psychodynamics of work, this article discusses the relevant literature on the problem of attracting nurses to ICU.
\end{abstract}

\section{Introduction}

The global healthcare system is in the midst of a major humanresources crisis (Conseil International des Infirmières, 2004), partly, it seems, because of the difficult working conditions in the field. Quebec too has been affected by the shortage of staff, particularly in the area of critical care [58] where the problem is more concentrated because of the high nurse-patient ratio. Quebec nurses used to regard intensive care units (ICU) highly, but now the large number of vacancies and the general lack of nurses there suggest that ICUs have lost much of their lustre. The situation is very worrying, for $50 \%$ of the nurses who practise in critical care have less than 5 years' experience [58] nursing in ICU is becoming ever more complex and more intense, and nurses cannot quickly acquire the specific skills they need to practise in ICU without the support of experienced peers. The aim of this article is to document current knowledge about the phenomenon of the declining popularity of ICUs among nurses. The theoretical framework of the psychodynamics of work (PDW) provides the backdrop for our analysis of the literature. Suggestions are made for courses of thought and action that could improve working conditions in ICUs and thus both halt the exodus of experienced nurses to other areas of practice and boost recruitment of new nurses.

Consultation of the main computerized healthcare databases brought to light 74 studies published between 1969 and 2008 that are relevant to our subject. Our final analysis was thus based on 19 theoretical and 55 empirical (44 quantitative and 11 qualitative) studies.

\section{The nature of nursing work in ICUs}

The ICU environment portrayed in the literature is hectic and noisy and bombards people in it with all sorts of stimuli. As early as 1972, Hay and Oken described nursing in ICU as a demanding practice that poses high emotional and physical risks in providing care to patients who are very ill and often fighting for their life. Today, ICU nurses have to work faster and faster with sick people whose needs are becoming more and more complex in a setting in which technology is always advancing.

The empirical-mainly quantitative-studies reviewed describe the sources of dissatisfaction or stress at work of ICU nurses and report on the methods used to try to manage them. The studies also underscore the malaise produced by the difficult working conditions that stem in turn from the nursing shortage. These quantitative studies were generally conducted using self-administered questionnaires, and they tend to favour the stress-coping approach, which, Estryn-Béhard (1997) points out, calls on individuals' ability to adapt to the demands of the work environment by drawing on their personal resources and the support of people around them.

\section{The sources of ICU nurses' suffering at work}

All the studies on mental health at work highlight the importance of the organization of work as a factor in suffering on the job. In PDW terms, suffering refers to the notion of psychological suffering and is related to the loss of pleasure, cooperation, solidarity, and social interaction [32]. Gilbert [39] defines workers' suffering due to the organization of work as "an extremely powerful force that is all too often ignored in interpreting behaviour on and off the job". He contends that suffering emerges when, among other things, work loses its meaning, and that it sets in motion a struggle on the part of the workers to maintain their psychological well-being [39]. The review of the literature provides some insight into various interrelated themes that are to varying degrees associated with the notion of stress. The particulars of the different analyses point to many signs of suffering among ICU nurses that can be deduced from the defensive strategies they employ [39].

\section{Working as a nurse in ICU: a high-tension practice}

Mark and Hagenmueller [53] note that ICU nurses have to make a great many decisions in their practice and often have to deal with nursing situations that are characterized by high levels of complexity, uncertainty, instability, and variability. Bakker et al. [12] show that the need for nurses to make many important decisions in their work in circumstances in which there is only limited latitude for decision making is an important stress factor for them. Similarly according to a qualitative study by Cronqvist, Lützén and Nyström [30], the dissonance created by these two contradictory elements- the duty to make decisions and the small latitude for making them- is a major source of stress for ICU nurses.

\section{Demands of the technology}

Grout [40] offers an excellent analogy for the intensity of nursing in highly technologized ICUs in comparing it to the work of air-traffic controllers in busy airports. Similarly, a qualitative study by Alasad [2] underscores the fact that new ICU nurses experience high levels of stress and fear before they achieve technological competence. Furthermore, some authors point out that nurses who are poorly prepared to use

*Corresponding author: Lise St-Pierre, Directrice de la qualité et des soins infirmiers, Centre de santé et services sociaux de Memphrémagog, principal investigator, Canada, E-mail: stpierre_lise@hotmail.com

Received October 27, 2011; Accepted November 10, 2011; Published November 16, 2011

Citation: St-Pierre L, Alderson M, Saint-Jean M (2011) Challenges and Issues in

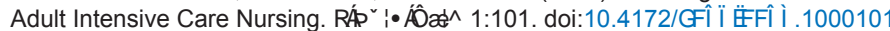

Copyright: (c) 2011 St-Pierre L, et al. This is an open-access article distributed under the terms of the Creative Commons Attribution License, which permits unrestricted use, distribution, and reproduction in any medium, provided the original author and source are credited. 
the technology suffer major stress and a feeling of overload that will lead them to focus dangerously on the equipment rather than on their patients $[45,77]$

\section{The heavy workload of ICU nurses}

In the early 1990s, the Quebec sociologist Carpentier-Roy [21] used the comprehensive psychodynamics of work approach to investigate nurses' work in ICU. She reported that the sources of anxiety are more plentiful in that environment than in other units. The author observed that the nurses have a greater responsibility vis-à-vis their patients in ICU than in other units. They are thus subject to different sources of anxiety, such as the fear of not being able to use the various and growing number of technological devices properly; the anxiety arising from the impossibility of offering patients and their family the support they need when they need it; and the fear of not recognizing the signs calling for urgent intervention quickly enough. According to Carpentier-Roy [21], the greatest sources of suffering for ICU nurses are psychological, and the fact that they have to deal with death on a daily basis is a central feature of the suffering for them.

Continuous evaluation of the patients' clinical condition comprises such an important part of nursing in ICU that it is hard for nurses to deal with anything unexpected when it occurs, further adding to the cognitive and psychological burden of their work [47,43]. The frequent interruptions demand additional intellectual effort on their part [43] in their descriptive study, Robinson and Lewis [62] report that the most important stressors ICU nurses identify include an atmosphere of crisis, which heightens psychological tensions, and the unavailability of an experienced physician in an emergency. In the frantic working environment of an ICU, in which the people under care are so highly dependent, nurses must stay calm and alert [21]. They cannot hesitate or make a mistake, for a patient may die if they do [43]. Furthermore, ICU nurses have to have a very high level of physical endurance because they spend extended periods on their feet and frequently have to move patients who are extremely heavy $[21,43,46]$.

\section{The perception of futile care}

For ICU nurses, many work situations are felt to run counter to their values or vision of care. Meltzer and Huckabay [54] note that there are many instances of what nurses perceive as aggressive therapy or nonbeneficial care and that there is a strong association between such perceptions and burnout among nurses. In a qualitative study of 25 ICU nurses in American hospitals, Badger [11] concludes that, for them, the perception of futile care is the most important stress factor at work.

\section{Lack of recognition at work}

Contemporary studies often raise the issue of the lack of recognition at work. Carpentier-Roy [21] observes that ICU nurses suffer more from lack of recognition for what they do and from the lack of power to match their responsibilities than from the actual physical demands of their work. Hay and Oken [43] report that the lack of gratification from patients affects the self-esteem of ICU nurses. In an analysis of the severity of stress factors, Robinson and Lewis [62] identify lack of recognition as one of the most important stressors that ICU nurses have to contend with.

\section{Personnel shortages and instability of experienced nursing staff}

Budget restrictions and a lack of resources often limit nursing numbers and have thus made it hard to deal with the demands of care when there is a sudden deterioration in the condition of some ICU patients $[28,53]$. This situation is quite common and is a major source of anxiety for ICU nurses [31,53]. In many ICUs, the vacancy rate for positions on the evening and night shifts has tended to increase so much that it has become common practice to resort to mandatory overtime and independent personnel (agency nurses). Indeed, for lack of staff, ICU nurses must often work two shifts in a row; that is, 16 hours in all. The overtime they work and the need to continually readjust their private life gives rise to fatigue, anxiety, anguish, and frustration in nurses.

In the face of these harsh working conditions, many experienced nurses are quitting the ICUs and are taking with them the experience and expertise that acted as a safety net in the provision of care. The vacancies they leave are often hard to fill, and the consequent lack of nurses frequently makes it necessary to close ICU beds temporarily. By reducing accessibility to beds on these units, these circumstances aggravate emergency-department overcrowding and prolong waiting times for major surgery that requires a stay in ICU. The situation thus negatively affects the performance of the entire Quebec healthcare system.

\section{Too short an integration period for new nurses}

The lack of nurses is so critical that, it has been observed, most ICUs no longer set eligibility criteria for nurses wanting to practise in them. However, clinical situations encountered in ICU are so complex they demand specific technical, technological and relational nursing skills as well as a finely honed clinical judgment that are acquired principally from working in the ICU environment and from the support of experienced peers [10]. Most of the experienced nurses who choose to stay in ICU are therefore continually obliged to act as preceptors to the new nurses [34] in the hope that the novices quickly become functional enough to pull their weight on the team. Thus, in addition to having to bear the loss of colleagues who have left the unit, nurses who remain on the job have to provide both clinical and psychological coaching and support to new nurses [23]. Furthermore, Alspash [10] stresses the fact that the time allotted to integrating new recruits into the ICU is often too short to allow them to appropriate the role of intensive-care nurse. Their psychological tension rises, and they feel very insecure when, after too short a period of integration and without much support, they have to assume overall management of two patients with complex needs. Many of them feel overwhelmed and decide to leave the ICU for other units [31]. The circumstances thus contribute to the very high turnover rate in ICUs and the heavier workload for the expert nurses who stay on the job and alone have to shoulder responsibility for providing all the care that patients on the unit require.

To sum up, the sources of suffering at work of ICU nurses that have been identified in the literature foreshadow danger for their mental health. ICU nurses experience a variety of situations and an organization of work that produce feelings ranging from slight discomfort to profound suffering. We shall now turn to the methods they use to protect themselves from such suffering.

\section{Defensive strategies used by ICU nurses}

According to Dejours [33], defensive strategies are behaviours workers use to lessen the perception of suffering. These mechanisms are not pathological per se [60] according to Alderson [6]; they are the very expression of what is problematic in the contemporary organization of nursing practice. Their purpose is to minimize perceived suffering rather than suppress it at its source, and they are implemented by workers in reaction to a restrictive organization of work and to work 
that no longer has meaning. The literature indicates that ICU nurses employ defence mechanisms to protect themselves from the suffering they have experienced.

It should first be noted that a great number of descriptive empirical articles report that ICU nurses use a variety of coping strategies to adapt to stressful situations. They may accordingly externalize their feelings to the group or engage in relaxation activities such as listening to music, doing aerobic exercise, watching television, walking, reading, seeking solitude, and going on vacation [11,55,59,62,76].

Secondly, Hay and Oken [43] report in their descriptive study that ICU nurses are usually more detached from their work than nurses in general wards because the ICU nurses use defence mechanisms that mitigate their perception of suffering. The mechanisms include denial of situations that are sources of suffering (for example, denying the anxiety associated with continual exposure to death); avoidance of the emotional impact of the work (for example, focusing on technical tasks rather than on the human aspect of care); and absenteeism (for example, taking a day off after a trying experience at work). In a comparative study, Maloney [51] observes that ICU nurses rationalize their feelings to protect themselves from difficult experiences on the job. In a recent qualitative study, Badger (2005) reports that ICU nurses use behavioural coping mechanisms in addition to the usual emotional and cognitive ones. Viewed as defensive strategies from a PDW standpoint, these behavioural mechanisms include withdrawal, avoidance and distancing oneself on the part of the nurse.

Thirdly, Carpentier-Roy [21] reports another common strategy used by ICU nurses: "the ideology of the elite". When an ICU nurse made statements stressing the high value attached to danger as a source of pleasure, the author noted that ICU nurses call on this elite ideology to protect them from the anxiety produced by psychological factors. The ideology serves as a defence strategy by reminding them that not everyone can be an intensive care nurse. According to Carpentier-Roy [21], it thus helps ICU nurses "bear the unbearable" by protecting them from the anxiety they are subject to.

Our review of the literature thus reveals that ICU nurses resort to a range of adaptation mechanisms that are appropriate when viewed in terms of a stress-coping approach or as defensive strategies undertaken to ease the perception of suffering or to resist assaults on their emotional well-being. As Carpentier-Roy [21] says, in ICUs there seem to be ways to release the often unavoidable psychological tensions that nurses experience. According to the PDW approach, individual nurses are likely to find such channels, which Alderson [8] calls "outlets," in their sources of pleasure at work.

\section{Sources of Pleasure at Work for ICU Nurses}

According to Alderson [7], "in the PDW approach, pleasure at work refers to the state of psychological well-being that workers experience when their work satisfies their desires for recognition and thus allows them to build their identity" PDW considers pleasure at work-like suffering-in collective terms. This section sets out the main sources of pleasure at work of ICU nurses mentioned in the literature. It should be noted that the sources of pleasure related to the organization of work are nowadays in continual decline for ICU nurses. In the literature they are usually expressed as factors that give rise to satisfaction and are very often the opposite of the sources of suffering.

A number of authors maintain that ICU nurses love challenges and like taking risks; in other words, they see stressful situations as motivating, as challenges rather than threats [21,52,64]. Lazarus [47] defines a challenge as a situation that gives a person a sense of well- being while producing stress or tension. In fact, Carpentier-Roy [21] notes that the constant challenge of danger and of the technology is one of the most common justifications nurses give for choosing intensive care; they enjoy the risk and the unpredictable nature of the work, where death is constantly lurking.

In a descriptive study of 96 nurses with at least one year's experience in ICU in Canada, Sawatzky [64] reports that the stressors the nurses see as stimulating or as challenging are emergencies, cases of cardiopulmonary arrest, patients who are unstable or in critical condition, responsibilities, decision making, unfamiliar situations, transfers, admissions as well as the aspects of a situation they may be unacquainted with but that lead them to outdo themselves. Similarly, Grout [40], who compares the work of ICU nurses in the United States to that of air-traffic controllers in a very busy airport, reports that the tasks that were presumed to be stressful for air-traffic controllers were shown to actually be sources of challenge and satisfaction for them; the pressure the air-traffic controllers experience proved to be the most attractive aspect of their work.

To sum up, our analysis of the literature shows that ICU nurses face several sources of suffering at work, which, for the most part, are associated with environmental and organizational factors rather than with the work itself. The literature suggests that the organization of work in ICUs demonstrates a level of rigidity that is related to a number of factors in the work environment and in management: the nurses' heavy workload; the omnipresent, highly demanding technology; the numerous routine operational tasks; rather inflexible work schedules on different shifts; and a strict management of human resources coupled with the unpredictable nature of the work. In addition, the lack of recognition for their work that nurses report seems to make their suffering even worse. The literature also shows that ICU nurses use a variety of coping mechanisms to try to adapt to the demands of their work and implement different defensive strategies to mitigate their perception of suffering. Analysis of the literature furthermore demonstrates that ICU nurses have sources of pleasure at work, and according to Carpentier-Roy [21], it is these sources of pleasure that make it possible for them to practise their profession with the freedom they need to accommodate the organization of ICU work to their wishes for fulfilment.

\section{Consequences of the current ICU work environment}

\section{Consequences for health outcomes}

A 2001 study by the Ordre des Infirmières et Infirmiers du Québec reports that the unmet need for nurses has grown in various sectors and has affected the quality of nursing. Indeed, in a descriptive study, Morrison et al. [57] reveal that errors tend to increase in ICUs in which very acute clinical situations are combined with a shortage of nurses and inadequate supervision. Beckman and Gillies [13] note that the failure of early detection of deterioration in patients' condition (failure to rescue) in ICUs tends to be exacerbated when there are not enough experienced nurses. Some authors point out that staffing levels and the collective competence of nurses may explain many aspects of patient morbidity and mortality $[2,3,61]$. It is interesting to note in this regard that the difficult working environment engenders individualism, hampers solidarity and undermines or limits the formation of true working groups. Such situations produce feelings of impotence in workers, leading them to turn in on themselves and disengage from their work [20].

\section{Consequences for nurses' health}

The consequences of the difficult working conditions in ICUs on 
the health of nurses must not be ignored. Unlike studies that seek mainly to identify or describe the methods ICU nurses use to adapt to stressful situations at work, the PDW approach seeks to understand the relationship between the way work is organized and the mental health of the workers [21]. Vézina [71] points out that from the standpoint of PDW, equilibrium on three dimensions-fulfilment through work, identity building and recognition by others-helps workers maintain their mental health. The author points out that by letting workers use their creativity, by encouraging initiative and by allowing them some autonomy, work enables people to fulfil themselves and develop their identity. In contrast, an organization of work that does little to foster creativity or initiative and leaves little room for negotiation, hinders identity building and consequently undermines psychological wellbeing [73]. When workers no longer have the opportunity to reflect on their work or to discuss situations they encounter with each other, the result is often that the work loses its meaning $[71,20]$. The present situation in ICUs seems to be of this second type.

Some studies on nursing have more particularly investigated the relationship between the environment of ICUs and the health of the nurses practising in them. Thus, as early as 1979, Oskin reported that in the United States measured stress levels of ICU nurses were associated with a health risk. More recently, other authors have pointed out that the high level of stress that ICU nurses experience engenders signs and symptoms of both a physical (e.g., headache, skin rash, gastrointestinal disorder, weight fluctuation) $[22,64]$ and psychological (e.g., loss of morale, burnout) nature that are associated with a loss of productivity [64].

Cronqvist et al. [31] maintain that when the workload is heavy, ICU nurses experience more stress, and absences for personal illness increase. Furthermore, Tummers et al. [70] and Le Blanc et al. [48] note that the heavy workload and prolonged stress of ICU nurses is correlated with burnout. Bakker et al. [12] observe that burnout-which Robinson and Lewis [62] define as related to continual exposure to stressors at work and to the use of ill-adapted coping strategies- is a serious problem for ICU nurses. In their study of burnout contagion, Bakker et al. [12] report that ICU nurses are more likely to present the problem if they work in a unit where the condition is highly prevalent. In addition, some authors point out that moral distress is a common response in ICU nurses who face ethical challenges [28,54].

Often, ICU nurses' time and energy is taken up with tasks beneath their skill level. Moreover, in a study that does not deal exclusively with ICUs, Bourbonnais et al. [15] found that nurses lack the time to practise aspects of their role that have a positive impact on the quality of care. The result is work comprised almost exclusively of technical actions that leave by the wayside the relational aspects of care, which, on a dayto-day basis, give meaning to a nurse's work [15]. Other authors add that this type of organization, which results in major work overload and a range of frustrations, helps increase turnover and burnout rates in ICUs $[48,53]$.

\section{Consequences for work relations}

Current circumstances in ICUs have produced major changes in nurses' interpersonal relations by undermining trust between colleagues and vis-à-vis management. As the staffing situation continues to deteriorate, nurses, who have little say in decision making and are subject to mandatory overtime, may suspect that management is not making sufficient effort to improve their lot. Indeed, according to Mishra and Morrisey [56] trust is closely related to employee participation in the decision-making process and to the sharing of information. Employees who are little involved in decision making may suspect that information is being kept from them, and so feel a growing distrust of management. Dejours [33] maintains that the lack or loss of trust by workers has an impact on team collaboration, mobilization and recognition.

Vézina [71] points out that the weakening of social relations between people leaves them bereft and disoriented, making peer recognition all the harder. Vézina [72] notes moreover that work situations that combine greater effort with little reward elicit both emotional and physiological pathological reactions. This combination seems to characterize the situation faced by a number of nurses working in ICU.

\section{To sum up}

The studies we reviewed suggest, from several different standpoints, that the three dimensions posited by Vézina [71] - fulfilment at work, identity building and recognition by others- are not in equilibrium in ICU nurses. In fact, the sources of suffering at work analyzed in the literature may be considered damaging for ICU nurses insofar as they considerably reduce any pleasure the nurses derive from their work and cause it to lose meaning for them.

The difficult environment and rigid organization of work intensify the factors for dissatisfaction in ICU and create an imbalance between the nurses' sources of pleasure and of suffering. According to Carpentier-Roy [20], the rigidity of the organization of work limits the nurses' potential to find emotional release, resulting in accumulated energy that induces "a feeling of displeasure and of suffering that can be accompanied by various psychological disorders." [5] Since their capacity for regulating suffering and defences is diminished by this rigidity, many ICU nurses feel threatened and implement defensive strategies that lead many of them to be frequently absent and even to leave the ICU in order to preserve their mental health. In fact, Vézina and Malenfant [75] maintain that sometimes individuals have no choice but to leave a job in order to reduce the tensions created by their work. The departure of many nurses destabilizes teams and weakens any working groups that may exist. The repercussions for the working climate are negative; they damage the image of ICUs and make work in such units less attractive to nurses. The effect on nurse recruitment and retention is substantial, and the suffering of the nurses who remain on the job is exacerbated. Some of them end up leaving these difficult working conditions. This situation aggravates the initial problem and reinforces the suffering that further saps their quality of life at work.

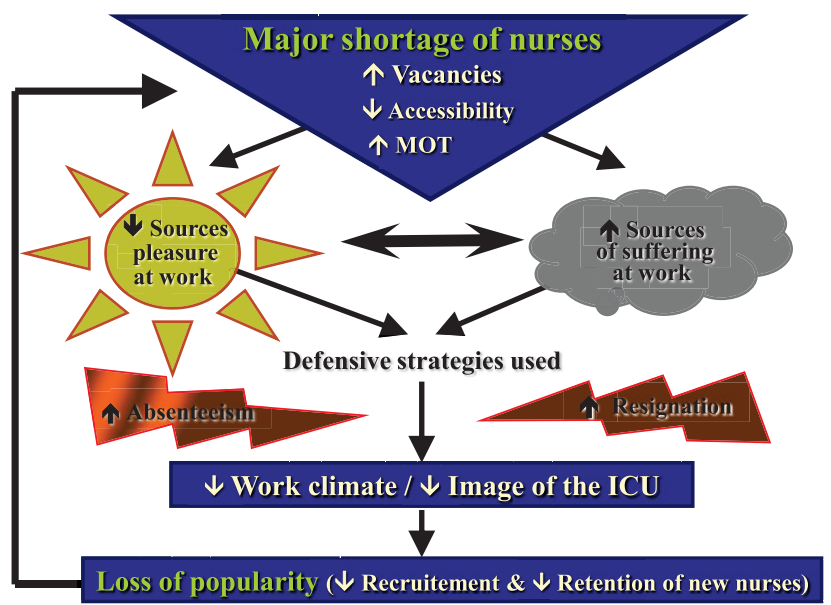

MOT: Mandatory overtime

Figure1 : Graphic summary of the analysis 
Citation: St-Pierre L, Alderson M, Saint-Jean M (2011) Challenges and Issues in Adult Intensive Care Nursing. J Nurs Care 1:101. doi:10.4172/

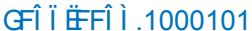

- Approach issues of stress at work from the angle of the organization of work by considering, among other things, demands for decision-making autonomy, recognition and social support at work.

- Undertake interventions that actively involve staff; for example, improve worker-employer dialogue; encourage participatory management, reduce hierarchy, raise workers' awareness of stress, and initiate relaxation activities.

- Ensure that an experienced physician is always present in ICU.

- When assigning patients to a nurse, take into account her experience, expertise in ICU and the complexity of the care to be provided.

- When organizing work, including nurse-patient ratios, take into account the uncertainty of the instability and variability of clinical situations in ICU.

- Provide the necessary healthcare-staffing support so that nurses can take breaks and have the time to discuss things with each other and regain their energy.

- Organizing interdisciplinary forums and discussion groups on ethics and reflective practices could help reduce moral distress by allowing staff to express their malaise about situations that cause them discomfort.

Hay \& Oken (1972)

Li \& Lambert(2008)

Mark \& Hagenmuller (1994)

Hay \& Oken (1972),

Vézina \& Carpentier-Roy (2000)

- Lower environmental noise levels and settle problems regarding the lack or poor condition of equipment.

Gurses \& Carayon(2007)

Sawatzky (1996)

IMPROVE THE HEALTH OF THE WORK ENMRONMENT

- Set up an organizational structure that gives priority to training and to the implementation and evaluation of six practice standards. These would involve, most particularly, communication skills, collaboration, decision making, adequate human resources, meaningful recognition, and authentic leadership.

- Improve and monitor the health of the work environment in order to retain experienced nurses so that they can support the novices.

$\operatorname{AACN}(2005)$

Stone et al. (2006)

Introduce interventions aimed at creating a positive organizational climate, similar to that in magnet hospitals

IMPROVE RECOGNIION

- Improve present mechanisms for recognition at work.

Stone et al. (2007)

ENHANCE SUPPORT FOR NURSES

- Provide enough support staff to lighten the workload for nurses.

- Create innovative roles for older nurses; e.g., mentor, quality educator to ensure application of best practices, safety officer, technology facilitator, relief nurse (replacement during breaks, help with transfers and transport, help with family support), etc.

- In anticipation of retirements, put into place systems to allow experienced nurses to stay on the job longer if they wish to; they could provide support for new nurses and thus lower their stress at work.

Carpentier-Roy in Legault Faucher (2005)

ADOPT A PARTICIPATORY MANAGEMENT STYLE

- Initiate interventions that centre on leadership style, team atmosphere and interpersonal dynamics in teams in order to improve satisfaction at work and help ICU nurses find fulfilment in their work

- Support the heads of ICUs in order to develop or reinforce a participatory management style, which should notably include:

- recognizing the contribution nurses make

- maintaining an effective information-sharing climate,

- creating opportunities for professional development,

- promoting decision making by nurses.

- Demonstrate flexibility in drawing up work schedules; marginal scheduling allows nurses more consecutive days off so that they can take some distance from their work.

IMPROVE THE INTEGRATION PERIOD AND CONTINUING EDUCATION

- Create a culture of retaining ICU nursing expertise instead of relying solely on attracting new nurses and exhausting the preceptors who are continually given responsibility for integrating the new nurses, only a tiny proportion of whom stay in ICUs.

- Integrating new nurses well and in a way that takes generational cohabitation into account.

- Enhancing integration programs, particularly by adapting teaching strategies to the needs of inexperienced new nurses, helps provide better support, reduce stress, and so ease the transition from the academic environment to the highly specialized ICU setting.

- During the integration period, include training sessions on death and care for the dying in order to reduce stress for new nurses who often are exposed to death for the first time in the ICU.

- Enhance the clinical competencies of nurses to lower the tumover rate and help make sure there is a stable, qualified team to provide safe patient care.

- Encouraging shared learning for nurses and physicians enhances collaborative relations between them and thus improves interpersonal relations and nurse satisfaction at work.

Table 1: Avenues for thought and action that are likely to improve working conditions in ICUs.

Hatcher et al. (2006)

Buerhaus et al. (2000)

Bakker et al. (2005)

Boyle et al. (1999)

Gibson (1994)

Ruggiero (2005)

Cll (2006)

Diehl-Oplinger \& Kaminski (2001)

Alspach (2003)

Cavanaugh, \& Huse (2004)

Hays et al. (2006)

Shirey \& Fisher (2008)

Hays et al. (2006)

Huckabay \& Jagla (1979)

Dracup \& Brown (1998)

Hays et al. (2006)

Stone \&Gershon (2006)

Chaboyer et al. (2001)

Leblanc et al. (2001)
It is important and urgent to break the vicious cycle described above, otherwise the accessibility of intensive care will be seriously affected, and the sustainability of the system threatened. However, the analysis does point to a number of avenues for thought and action, which will be presented below.

Figure 1 provides a graphic summary of the analysis. Drawing on the principal concepts of PDW, it shows the negative circular movement produced by the organization of nurses' work and prevailing circumstances in ICUs.

\section{Avenues for Thought and Action}

The studies we analyzed point to a number of avenues for thought and action that may improve working conditions in ICUs. They are described briefly below and summarized in Table 1 .

The better-known approach to stress generally calls on individuals to adopt coping mechanisms in order to adapt to sources of stress in the work environment. The psychodynamics of work approach advocates transforming the organization of work so that it is more conducive 
to satisfying workers' desires for identity building and fulfilment and provides greater support for their mental health [33]. When workers regain some control over their work situation and sources of suffering are reduced, work regains its meaning [71] and mental-health problems become less acute [7].

According to Burke [17], over time organizational approaches to health at work have a more long-lasting effect than those that emphasize the role of the individual. Similarly, Stone et al. [68] maintain that interventions that seek and provide for a positive organizational climate tend to reduce intentions to leave among ICU nurses.

Vézina [71] contends that, if the organization of work is to be transformed, it is important that workers become aware of the sources of suffering in their working environment so that they can try as a group to transform them into sources of meaning and pleasure [9]. Dracup and Brown [35] maintain that healthcare-system managers must first recognize that the ICU nurses' workload is growing heavier due to advances in technology and professional practice and to the growing complexity of clinical situations associated with an aging population. Management must thus become aware of the suffering ICU nurses experience and its impact on their health and on cares outcomes. In this regard, Robinson and Lewis [62] suggest improving managers' communication and problem-solving skills so that they can give their employees support. They also suggest offering ICU nurses a stress-management program that would include methods for the early detection of the signs and symptoms of increased stress levels so that they can take action as quickly as possible. While this solution may, on the face of it, be interesting, it should be considered cautiously, for responsibility would lie solely with the individual. For her part, Carpentier-Roy [20] underscores the point that management should listen to workers and consider their needs, wishes and suggestions.

In an interview with Legault Faucher [49], Carpentier-Roy declared that it is above all important to improve current mechanisms for recognition at work. It is not enough, she said, to recognize employees for the results they attain so that they will perform better. They must also be recognized for their commitment and the energy they put into their work, in order, particularly, to support or stimulate their motivation. According to Carpentier-Roy [19], speech- an indispensable tool for implementing recognition strategies-is a first step in the act of change. She maintains that it is necessary that individuals at work be able to offer each other recognition, for recognition enhances the sense of belonging to a group, reduces recourse to individual defensive strategies and improves staff retention. Furthermore, Vézina and Carpentier-Roy [20] consider that the lack of opportunities for people to reflect on their work and the lack of time and space to talk about it and about their experiences often result in work losing its meaning for them and consequently affect how much they invest in it.

\section{Avenues for Further Research}

Looking to the future, psychodynamics of work studies of ICU nurses would be useful; as Trudel [69] points out, an understanding of collective work experiences would lead to their being appropriated in the workplace and their becoming instruments for transforming the organization of nurses' work. The Canadian Health Services Research Foundation suggests focusing research on the evaluation of nurserecruitment and -retention activities and projects. White and Tonkin [76] propose evaluating the impact of a continuing-education program on the stress of ICU nurses, while Chaboyer et al. [24] advocate research to examine the relationship between the meaning of work, satisfaction at work and the turnover rate for ICU nurses.

\section{Conclusion}

This paper is an original examination of the relevant literature conducted in the light of the psychodynamics of work (PDW) approach. Its purpose is to document the problem of the decreasing popularity of intensive-care work among nurses. By highlighting the sources of psychological suffering and of pleasure at work for ICU nurses, our reading or rereading of the literature suggests that the current healthcare environment in Quebec and the way work is presently organized in ICUs are undermining the health of the nurses who practise there.

The analysis of the issue through the prism of PDW opens up interesting avenues for thought and action for promoting health at work and preventing health problems associated with current nursing practice in ICUs. All that remains is to hope that the suggested interventions help healthcare establishments take action on the way ICU nurses' work is organized so as to adapt the units better to the nurses rather than constantly demand that the nurses adapt to conditions in the units. For, as we noted earlier, some of the employers' demands are beyond the workers' capacity to adapt. Interventions are needed to reduce the health risk to ICU nurses and again make nursing in intensive care an attractive option.

In the face of such clear-cut evidence of the risk both to the mental health of nurses and the quality of care outcomes in ICUs, organizations can hardly disregard the avenues for thought and action that have been laid out. It is therefore vital in the short term to apply interventions to deal with the factors that have been identified as problematic. To ensure that intensive care is accessible and adequately meets the needs of clienteles with ever-increasing care requirements, ICUs need a sufficient number of nursing personnel who are ever more competent, ever more effective, and ever healthier. It would thus be advisable for organizations in the healthcare system to consider the avenues for thought and action that emerge from this analysis and seek to make ICUs once again attractive to nurses and so help improve the quality and safety of care in them. As Collière says, "We must reinvent care so that is invigorating, adapted to life, disalienating, and gives back meaning to the life both of those who receive it and who give it." [25].

\section{References}

1. American Association of Critical Care Nurses (AACN) (2005) Standards for establishing and sustaining Healthy work environments.

2. Aiken LH, Sloane DM \& Lake ET (1994) Lower medicare mortality among a set of hospitals known for good nursing care. Medical Care 32: 771-787.

3. Aiken LH, Sloane DM \& Sochalski J (1998) Hospital organisation and outcomes Quality in Health Care 7: 222-226.

4. Alasad $J(2002)$ Managing technology in the intensive care unit: the nurses' experience. International Journal of Nursing Studies 39: 407-413.

5. Alderson $M(2005)$ La souffrance psychique des infirmières. Est-ce pertinent de l'investiguer au moyen de la psychodynamique du travail?. Frontières 17: 53-58.

6. Alderson M (2004a) La difficile construction identitaire des infirmières: un facteur prédisposant aux problèmes de santé mentale. Le Vis-à-vie, Association québécoise en prévention du suicide, 14: 9-13.

7. Alderson M (2004b) La psychodynamique du travail : objets, considérations épistémologiques, concepts et prémisses théoriques. Santé mentale au Québec 29: 243-260.

8. Alderson M (2004c) La psychodynamique du travail et le paradigme du stress : une saine et utile complémentarité en faveur du développement des connaissances dans le champs de la santé mentale au travail. Santé mentale au Québec 29: 261-280.

9. Alderson, M. (2001) Analyse psychodynamique du travail infirmier en unité de soins de longue durée: entre plaisir et souffrance. Doctoral thesis. Faculté des sciences infirmières. Université de Montréal. 
10. Alspach JG (2003) Recognizing and Rewarding Nurse Preceptors in Critical Care. Critical Care Nurses 23: 13-19.

11. Badger JM (2005) A descriptive study of coping strategies used by Medical Intensive Care Unit nurses during transitions from cure- to comfort-oriented care. Heart \& Lung 34: 63-68.

12. Bakker AB, Le Blanc PM, Schaufeli WB (2005) Burnout contagion among intensive care nurses. Journal of Advanced Nursing 51: 276-287.

13. Beckmann U, Gillies DM. (2001) Factors associated with reintubation in intensive care: an analysis of causes and outcomes. Chest 120: 538-42.

14. Lindberg EB (2007) Increased Job Satisfaction After Small Group Reflection on an Intensive Care Unit. Dimensions of Critical Care Nursing, 26: 163-167.

15. Bourbonnais, R., Malenfant, R., Viens, C., Vézina, M., Brisson, C., Laliberté, D., et al. (2000). Les impacts positifs et négatifs de la transformation du réseau de la santé sur la vie professionnelle, la vie familiale et la santé des infirmières et des infirmiers de l'agglomération de Québec, Research report, CQRS, 1-27 and ii-iv.

16. Boyle DK, Bott MJ, Hansen HE, Woods CQ, Taunton RL (1999) Managers' leadership and critical care nurses' intent to stay. American Journal of Critical Care 8: 361-371

17. Burke R J (1993) Organizational-level interventions to reduce occupational stressors. Work and Stress 7: 77-87.

18. Buerhaus PI, Staiger DO, \& Auerbach DI (2000) Why are shortages of hospita RNs concentrated in specialty care units? Nursing Economics 18: 111-116.

19. Carpentier-Roy M-C (2007) Reconnaissance au Travail : Un élément essential de plaisir et d'efficacité au travail. Lecture given at the Hôpital MaisonneuveRosemont during the Semaine de la reconnaissance du C. H., Montréal.

20. Carpentier-Roy M-C (2000) Être reconnu au travail : nécessité ou privilège? In Actes du colloque Travail, reconnaissance et dignité humaine, Montreal.

21. Carpentier-Roy M-C (1990) Organisation du travail et santé mentale chez les infirmières en milieu hospitalier, Unpublished doctoral thesis, Université de Montréal, Département de sociologie, Faculté des arts et des sciences.

22. Cavalheiro AM, Moura Junior DF, \& Lopes, AC (2008) Stress in nurses working in intensive care units. Rev Lat Am Enfermagem 16: 29-35.

23. Cavanaugh DA, Huse AL (2004) Surviving the nursing shortage: developing a nursing orientation program to prepare and retain intensive care unit nurses. Journal of Continuing Education in Nursing 35: 251-256.

24. Chaboyer W, Najman J, Dunn S (2001) Factors influencing job valuation: a comparative study of critical care and non-critical care nurses. International Journal of Nursing Studies 38: 153-161.

25. Collière MF (2001) Soigner... Le premier art de la vie. Second edition. Paris: Masson

26. Conseil International des Infirmières (2006) La pénurie mondiale de personnel infirmier : domaines d'action prioritaire, Geneva, Switzerland.

27. Conseil International des Infirmières (CII) (2004) La pénurie mondiale d'infirmières diplômées- aperçu des questions et des solutions: Initiative mondiale pour la révision des soins infirmiers, Geneva, Switzerland.

28. Corley MC, Elswick R K, Gorman M, Clor T (1995) Moral distress of critical care nurses. American Journal of Critical Care 4: 280-285

29. Cronqvist A, Burns T, Theorell T, Lützen K (2004) Caring about- Caring for: moral obligation and work responsibilities in intensive nursing. Nursing Ethics 11: 63-76.

30. Cronqvist A, Lützén K, Nyström M (2006) Nurses' lived experiences of mora stress support in the intensive care context. Journal of Nursing Management 14: 405-413.

31. Cronqvist A, Burns T, Theorell T, Lützen K (2001) Dissonant imperatives in nursing: a conceptualization of stress in intensive care in Sweden. Intensive and Critical Care Nursing 17: 228-236.

32. Dejours C (1999) Incidences psychologiques des nouvelles formes d'organisation du travail, du management et de la gestion des entreprises. Archives des maladies professionnelles et de médecine du travail, 60: 533-541.

33. Dejours C (1993) De la psychopathologie à la psychodynamique du travail. Dans Travail et usure mentale, Reissue. Bayard, Paris, 205-219.

34. Diehl-Oplinger L, Kaminski MF (2001) Need critical care nurses? Inquire within. Dimensions of Critical Care Nursing 20: 30-32.
35. Dracup K, Bryan-Brown CW (1998) One more critical care nursing shortage. American Journal of Critical Care 7: 81-83.

36. Estryn-Behar M (1997) Stress et souffrance des soignants à l'hôpital Reconnaissance, analyse et prévention, Paris, Éditions Estem.

37. Fondation canadienne de recherche sur les services de santé (FCRSS) (2006) Les maux qui affligent nos infirmières Examen des principaux facteurs qui portent une incidence sur les ressources humaines infirmières au Canada.

38. Gibson V (1994) Does nurse turnover mean nurse wastage in intensive care units? Intensive and Critical Care Nursing 10: 32-40.

39. Gilbert MA (1995) Psychodynamique du travail et syndicalisme dans Plaisir et souffrance : Dualité de la santé mentale au travail, Actes du colloque Les aspects sociaux et psychologiques de l'organisation du travail. May 1994. Montreal, Acfas, 66-72.

40. Grout JW (1980) Occupational stress of intensive care nurses and air traffic controllers: review of related studies. Journal of Nurse Education 19: 8-14.

41. Gurses AP, Carayon P (2007) Performance Obstacles of Intensive Care Nurses. Nursing Research 56: 185-194.

42. Hatcher J, Bleich MR, Connoly C, Davis K, O'Neill Hewlett P, Stokley Hill K (2006) Wisdom at work: the importance of the older and experienced nurse in the workplace. Princeton, NJ: Robert Wood Johnson Foundation.

43. Hay D, Oken D (1972) The psychological stresses of ICU nursing. Psychological Medicine, 23: 109-118.

44. Hays M, All AC, Mannahan C, Wallace D (2006) Reported Stressors and Ways of Coping Utilized by Intensive Care Unit Nurses. Dimensions of Critical Care Nursing 25: 185-193

45. Huckabay LMD, Jagla B (1979) Nurses' stress factors in the intensive care unit Journal of Nursing Administration 9: 21-26.

46. Hudack CM, Gallo BM, Gonce Morton P (1997) Rewards and challenges of critical care nursing: a holistic approach. In C. M. Hudack, B. M.Gallo, \& P. Gonce Morton (Eds.), Critical Care Nursing. $7^{\text {th }}$ ed. Philadelphia, PA: Lippincott, 93-102.

47. Lazarus RS (1966) Psychological stress and the coping process, New York, Mc Graw-Hill.

48. Le Blanc PM, De Jonge J, De Rijk AE, Schaufeli WB (2001) Well-being of intensive care nurses (WEBIC): a job analytic approach. Journal of Advanced Nursing. 36: 460-470.

49. Legault Faucher M (2005) Le travail, la subjectivité, le sujet et l'acteur Attention, ne pas séparer! Prévention au travail, 46-47.

50. Li J, \& Lambert VA (2008) Job satisfaction among intensive care nurses from the People's Republic of China. Int. Nurs. Rev 55: 34-39.

51. Maloney JP (1982) Job stress and its consequences on group of intensive care and non-intensive care nurses. Advances in Nursing Science 4: 31-42.

52. Maloney J, Bartz C (1983) Stress-tolerant people: intensive care nurses compared with non-intensive care nurses. Heart Lung 12: 389-394.

53. Mark BA, Hagenmueller AC (1994) Technological and environmental characteristics of intensive care units: implications for job redesign. Journal of Nursing Administration 24: 65-71.

54. Meltzer LS, Huckabay LM (2004) Critical Care Nurses' Perceptions of Futile Care and its Effect on Burnout. American Journal of Critical Care 13: 202-208.

55. Miranda EF (1980) Stressful situations and coping mechanisms of intensive care unit nurses at $X$ hospital. Papers 16: 21-28.

56. Mishra J, Morrisey M (1990) Trust in employee/employer relationships: A survey of West Michigan managers. Public Personnel Management 19: 443463

57. Morrison AL, Beckmann U, Durie M, Carless R, Gillies DM (2001) The effects of nursing staff inexperience (NSI) on the occurrence of adverse patient experiences in ICUs. Australian Critical Care, 14: 116-21.

58. Ordre des infirmières et infirmiers du Québec (OIIQ) (2008) Bulletin d'information des conseils des infirmières et infirmiers.

59. Oskin SL (1979) Identification of situational stressors and coping methods by intensive care nurses. Heart \& Lung 8: 953-960.

60. Pauchant T, Mitroff I (1995) Le niveau existentiel : L'individu et ses défenses. In La gestion des crises et des paradoxes, Montreal, Québec Amérique, ch. 7: 87-101. 
61. Prescott P (1993) Nursing: An important component of hospital survival under a reformed health care system. Nursing Economic\$11: 192-199.

62. Robinson JA, Lewis DJ (1990) Coping with ICU work-related stressors: a study. Critical Care Nurse 5: 80-88.

63. Ruggiero JS (2005) Health, Work Variables, and Satisfaction among Nurses. Journal of Nursing Administration 35: 254-263.

64. Sawatzky JV (1996) Stress in critical care nurses: Actual and perceived. Heart \& Lung 25: 409-417.

65. Shirey MR, Fisher ML (2008) Leadership Agenda for Change toward Healthy Work Environments in Acute and Critical Care. Critical Care Nurse 28: 66-79.

66. Stone PW, Gershon RR (2006) Nurse work environments and occupationa safety in intensice care units. Policy, Politics, \& Nursing Practice 7: 240-247.

67. Stone PW, Larson EL, Mooney-Kane C, Smolowitz J, Lin SX, et al. (2006) Organizational Climate and Intensive Care Unit Nurses' Intention to Leave. Critical Care Medicine 34: 1907-1912.

68. Stone PW, Mooney-Kane C, Larson EL, Pastor DK, Zwanziger J, et al. (2007) Nurse working Conditions, Organizational Climate, and Intent to Leave in ICU: An Instrumental Variable Approach. Health Serv Res 42: 1085-104.

69. Trudel $L$ (2000) S'engager dans une enquête en psychodynamique du travail : réflexions méthodologiques. In M-C. Carpentier-Roy \& $M$. Vézina (Eds.), Le travail et ses malentendus. Quebec: Les presses de l'Université Laval, 42-52.

70. Tummers GER, Van Merode GG, Landeweerd JA (2002) The diversity of work differences, similarities, and relationships concerning characteristics of the organization, the work and psychological work reactions in intensive care and nonintensive care nursing. International Journal of Nursing Studies 39: 841-855.

71. Vézina $M(2000)$ Les fondements théoriques de la psychodynamique du travail. In M. C. Carpentier-Roy \& M. Vézina (Eds.), Le travail et ses malentendus, Enquête en psychodynamique du travail au Québec. Octares, Les Presses de l'Université Laval, 29-41.

72. Vézina M (1999a) Organisation du travail et santé mentale : état des connaissances et perspective d'intervention. Revue de médecine au travail 26 : $14-24$.

73. Vézina M (1999b) Stress et psychodynamique du travail: de nouvelles convergences, Travailler, Revue internationale de psychopathologie et de psychodynamique du travail 1: 201-218.

74. Vézina M, Carpentier-Roy MC (2000) Discussion générale et conclusion. In M.C. Carpentier Roy \& M. Vézina (Eds.), Le travail et ses malentendus. SaintNicolas, Quebec, Les Presses de I'Université Laval, 147-155.

75. Vézina M, Malenfant R (1995) Dualité de la santé mentale au travail. In Plaisir et souffrance : Dualité de la santé mentale au travail, Actes du Colloque Les aspects sociaux et psychologiques de l'organisation du travail, May 1994 Montreal, ACFAS, 5-9.

76. White D, Tonkin J (1991) Registered nurse stress in intensive care units: an Australian perspective. Intensive Care Nursing 7: 45-52.

77. Wilkinson $P$ (1992) The influence of high technology care on patients, their relatives and nurses. Intensive and Critical Care Nursing 8: 194-198. 